\title{
Deconstructing affect: Posthumanism and Mark Hansen's media theory
}

Cecchetto, David

Suggested citation:

Cecchetto, David (2011) Deconstructing affect: Posthumanism and Mark Hansen's media theory. Theory, Culture \& Society, 28 (5). pp. 3-33. ISSN 0263-2764 Available at http://openresearch.ocadu.ca/id/eprint/1354/

Open Research is a publicly accessible, curated repository for the preservation and dissemination of scholarly and creative output of the OCAD University community. Material in Open Research is open access and made available via the consent of the author and/or rights holder on a non-exclusive basis.

The OCAD University Library is committed to accessibility as outlined in the Ontario Human Rights Code and the Accessibility for Ontarians with Disabilities Act (AODA) and is working to improve accessibility of the Open Research Repository collection. If you require an accessible version of a repository item contact us at repository@ocadu.ca. 


\title{
Deconstructing Affect: Posthumanism and Mark Hansen's Media Theory
}

\begin{abstract}
In the context of the highly contested discourse of posthumanism, this essay examines Mark Hansen's attempt to give a robust account of technology in its extra-linguistic dimension by evincing an '"originary" coupling of the human and the technical' that grounds experience as such (Hansen $2006 a$ : 9 ). Specifically, I argue that Hansen's perspective is haunted by the representational logic that it moves against. In this, I do not repudiate Hansen's argument as such, but rather reject one of its central underlying implications: that the extra-discursive materiality of technology might be accessed, linguistically, without attaching a meaning to it that is foreign to this materiality. To this end, the essay begins with an examination of technesis as it is initially developed by Hansen, demonstrating the necessity from which it sprang, the contribution that Hansen's reading makes, and its ultimate limitations. From here, the essay articulates Hansen's argument for an affective topology of the senses, corroborating the increased importance of digital technologies in this perspective through a brief comparison of Roberto Lazzarini's 'skulls' (as read by Hansen) and my own piece 'Sound.' Finally, this comparison pivots the essay towards a critical analysis of Hansen's account of primary tactility that demonstrates its dependence on the (representational) logic of language. In closing, then, I argue that what is accomplished by Hansen's putting-into-discourse of technesis is,
\end{abstract} paradoxically, a re-staging of the constitutive ambivalence of deconstruction that reinvigorates the posthumanist elements of that discourse.

Keywords: Affect, posthuman, performativity, media theory, art, autopoiesis, sound

"The potential of deconstructive analysis lies not in the simple recognition of the inevitability of exclusions, but in insisting upon accountability for the particular exclusions that are enacted and in taking up the responsibility to perpetually contest and rework the boundaries" (Barad 1998: 104).

Today, the signs of technological posthumanism have become so ubiquitous that most of us, on most occasions, have ceased to take notice. Indeed, our navigations through diverse realities and our negotiations with aggressive technological couplings are no longer even really remarkable: email and video-chats, certainly, but also medical imaging, online classes, virtual exercise routines, and complex relational databases are all part of our daily lives. As a result, our perceptive apparatuses are constantly tuned to diverse and often contradictory frequencies, but in a way that tends to play out any incongruities as part of what and who we are as humans. Indeed, many of us are more likely to feel the absence of these technologies than their presence: for example, I frequently feel a visceral frustration at not having Internet access while driving; a question pops into my head and — before becoming aware of my physical situation—I can feel my body reaching for the Internet to answer it. What feels incongruent is not having the Internet available, as it forces me back into the confines of a body that I no longer identify as being the sum total of my self. Indeed, even as I feel this bodily re-containment as a reductive violence played out on my consciousness, I nonetheless continue to hurtle along the highway at a speed that insists that I too am propelled, just as much as my automobile. 
Two things are revealed in this scenario: firstly, that to the extent that our agency pertains to our actions in the world, we are today compelled to think of ourselves through the lens of technology; secondly, that this has always been the case. Of course, if the second point is true, then we can safely say that the first point is not a new one. However, one feature that separates our current mixed reality — the mixed reality of digital and analogue technologies — from that of the past is precisely the fact that we are able to marvel at our own ability to navigate so seamlessly from one realm to another. As Mark Hansen notes, the question of how we can accomplish this feat so fluidly 'did not need to be posed so long as perceptual experience (with only atypical exceptions) remained within a single experiential frame — so long, that is, as experience typically occurred within a single perceptual world as a coupling to a single form of extension or homogeneous outside' (2006a: 8).

These, then, are the conditions of our posthumanity, conditions that highlight the continued importance of investigating the relations between humans and technology. ${ }^{\mathrm{i}}$ As a result, the stakes of any particular construction of posthumanism also loom large today: presuming that the constraints within which we construct posthumanism as a problematic will directly inform what we posthumans are revealed to be (and to have been), drawing out the predicates of a particular thinker's narration of human-technology relations becomes paramount to understanding the effects that narration will have. Simply put, if posthumanism aims to register the changing relations of humans and technologies - or, more broadly, the complex interactions 'between individuals as living beings and the historical element' (Agamben 2009: 6) — this essay starts from the position that such registration is not (and cannot be) neutral, so that the task of a would be cultural theorist is to uncover such bias, and to unpack the perspective that it services. 
These are the stakes of this examination of Mark Hansen's construction of posthumanism - which I call organismic posthumanism - particularly as it is presented in his three key texts Embodying Technesis, New Philosophy for New Media, and Bodies in Code. ${ }^{\mathrm{ii}}$ While the subject matters of these texts frequently overlap, the primary focus of each nonetheless unfolds distinct components of Hansen's expanding argument for a posthuman view that simultaneously avows the radical (as opposed to relative) exteriority of technology and the primacy of embodiment: Embodying Technesis unpacks the 'putting-into-discourse' of technology as it has taken place across otherwise divergent strains of contemporary theory, showing how this action disavows technology's material specificity; New Philosophy for New Media insists that there is an affective topology of human perception that is fundamentally tactile, encompassing vision such that the latter relates to a primordial 'haptics' that grounds it; and Bodies in Code synthesizes these perspectives, insisting more strongly than either previous book that technology is bound up in human embodiment itself, and that we can thus best understand human technogenesis through a re-reading of the operational perspective invoked by theorists of autopoiesis. Collectively, then, Hansen's oeuvre seeks to give 'a robust account of technology in its irreducible materiality that exists beyond discourse and representation' (Hayles 2000: 7), while also evincing an “originary" coupling of the human and the technical' that grounds experience as such, and which 'can only be known through its effects' (Hansen 2006a: 9).

Put simply, I argue that Hansen's perspective is ultimately haunted by the representational logic that it moves against. In this, I do not repudiate Hansen's argument as such, but rather reject one of its central underlying implications: that the extra-discursive materiality of technology might be accessed, linguistically, without attaching a meaning to it that 
is foreign to this materiality. Such access, then, generates a bias that is naturalized through the notion of technology per se, since the latter masks its contingency. In particular, I argue that this bias is already nascent in Embodying Technesis as the concept of technesis itself, and that it reaches full maturity in the organismic perspective that grounds the title-term of Bodies in Code. To this end, the essay begins with an examination of technesis as it is initially developed by Hansen, demonstrating the necessity from which it sprang, the contribution that Hansen's reading makes, and its ultimate limitations. From here, the essay articulates Hansen's argument for an affective topology of the senses, corroborating the increased importance of digital technologies in this perspective through a brief comparison of Roberto Lazzarini's skulls (as read by Hansen) and my own piece Sound. Finally, this comparison pivots the argument towards a critical analysis of Hansen's robust account of primary tactility, an analysis that concludes the essay by agreeing with most of Hansen's assertions, but also by insisting that they remain within the (representational) logic of language. In closing, then, I argue that what is accomplished by Hansen's putting-into-discourse of technesis is, paradoxically, a re-staging of the constitutive ambivalence of deconstruction that shows the latter to be a promising premise for specifying the relation between humans and technology.

$* * *$

Embodying Technesis came into print in the midst of what Hansen identifies as a shift in science and technology studies, moving towards a paradigm that gives precedence to concrete experiential effects over abstract theoretical significance. This change was necessitated by the dramatic disjunction existing between technologists and theorists of technology, aptly summarized by Hayles:

From the point of view of the technologist, the critical theorist knows nothing about the workings of technology and demonstrates it by talking in terms so abstract that material objects are vaporized into mere words; from the point of view of the theorist, the technologist is so stuck on nuts and bolts that he remains 
oblivious of the fact that these objects are never simply present in themselves, being always already enframed by cultural assumptions and mediated by discursive practices. (2000: v)

Thus, with the aim of conjoining material practice with theoretical sophistication, the conventional 'top-down "diffusion" model' of analysis has been increasingly replaced by translative approaches that attend to the minutiae of everyday activity. ${ }^{\text {iii }}$ As emblematic of this perspective, Hansen cites Isaac Asimov's famous suggestion that the lived experience of modern man has been more dramatically shaped by practical inventions such as the automobile than it has by more (discursively) consequential shifts in scientific knowledge like Einstein's theory of relativity. What require attention, in this view, are thus not the major events, ruptures, or characteristics that are readily available as objective knowledge in a historical macro-narrative, but rather the complex relations that contextualize these events and comprise the ground for the narrative itself (Hansen 2000: 1-2).

This is a shift that Hansen agrees with in principal, so that the task he finds currently at hand is to specify the ways that everyday technologies profoundly impact our lives, rather than simply insisting that they do so. However, in the case of technology this is not so simply accomplished, because 'technologies underlie and inform our basic "ways of seeing" the world' (Hansen 2000: 2-3): the ways in which our daily activities presuppose technology function to foreclose the possibility of analyzing them in isolation. As a result, Hansen insists that 'despite its irreducible concreteness, technology's experiential impact must accordingly be considered to be first and foremost indirect and holist' (2000: 2). In short, to the extent that technologies structure perception they also elude it, resulting in the tremendous difficulty—perhaps even the impossibility—of thinking technology 'in its own terms.'

For Hansen, this evasion not only explains the tendency to think technology abstractly, but also leads to what he calls the 'culturalist assimilation of technology' (2000: 3). In this latter 
case, Hansen insists that all too frequently the (true) observation that technologies cannot exist outside social systems is conflated with the (false) claim that they can 'be captured by the interpretive tools germane to such systems' (2000: 3). Thus, Hansen does not take issue with the culturalist position that understands technology to be part of a complex social network, but he is resolute that technology is also more than this, and radically so.

Indeed, it is precisely this radicality that is at stake in Hansen's overall project, as one of the motivating factors in his writing is the claim that twentieth-century theoretical texts 'from Freud and Heidegger to Lacan, Derrida, and Deleuze and Guattari' (Hansen 2000: 93) relativize the exteriority of technology, subordinating it to the more central overriding theoretical purposes of each of their intellectual projects. In this, these theorists interpret the 'host of concrete materializations through which technologies impact our practices [...] according to "logics" that are strongly posthermeneutical,' ignoring the fact that technology influences our embodied lives 'at a level below the "threshold" of representation' (Hansen 2000: 4). iv In so doing, technology is rendered an object of knowledge, and is thus exchangeable for other objects within the logic of representation. Simply put, so long as technology is taken to be grounded in representation, its (for Hansen innate) potential to intervene from outside of this system is effaced.

Hansen uses the term technesis to account for this representationalist reduction, defining it firstly as the 'putting-into-discourse' of technology. Crucially, Hansen argues that technesis not only reduces technology by underspecifying it, it actually alters the materiality of technology by re-specifying it differently. Simply put, 'technology itself' disappears in technesis except in the form of alibi. The representation of technology through technesis bears as much similarity to the material specificity of technology as a bank robber wearing a Richard Nixon mask bears to the former American president; in both cases, the contents of the mask (i.e. technology and 
Nixon's facial features) are subjugated to the logic of the events in which they are staged (i.e. language and a bank robbery).

Hansen offers numerous ways in which this representationalist reduction is enacted, emphasizing how in each case technology is abstracted into a disciplinary logic that discursively precedes it, ignoring the fact that (for Hansen) technology exists in its own right within a strata of reality that is fundamentally pre-discursive. ${ }^{\mathrm{v}}$ Importantly, each example that Hansen offers flows from a broader critique of Derrida's deconstructive grammatology, particularly its claimin Hansen's view—for language as 'the exclusive or privileged faculty of experience' (Hansen 2000: 14). Via a critique of grammatology, Hansen mounts his thesis that technesis employs technology as an abstract cipher for an internal otherness that, while constitutive of texts, does not pertain to technology. In short, he argues that linguistic logocentrism—despite manifold claims to the contrary—continues to dominate the various ways in which technology has been engaged within (at least western) philosophical discourse.

However, this critique of Derrida merits further consideration. Hansen's argument specifies that within Derrida's work technology is consistently restricted to a 'model of the text as machine' (2000: 86). In particular, he sees in Derrida (as in other twentieth-century poststructuralist theorists) an inversion of the machine metaphor as it had developed since at least the seventeenth century (predominantly in the form of the clock), wherein machines were 'consistently employed as a heuristic for conceptualizing what is proper to the human' (2000: 84). Through this inversion, a machinic ontology of textuality is produced wherein 'language assumes the role of a machine that runs independently of the phenomenal and rhetorical categories governing lived experience' (Hansen 2000: 82) such that 'for the first time, the machine is actually deployed as a metaphor for technology itself' (Hansen 2000: 83). In this, 
Hansen argues, technology is domesticated by Derridean textuality, such that it is dependent on the movement of differrance to the same extent that writing (in the restricted sense) is. As such, technology is not a site of inquiry in its own right, but is rather restricted to a 'doubly derivative status' that simply lends support to 'the totalizing grasp of [Derrida's] ontology of différance' (2000: 85).

The merit of this critique of Derrida is that it articulates, constatively and performatively, the tremendous difficulty of the task that Hansen has set himself in trying to account for technology 'in its own terms.' Its drawback, though, is that it rests on a fundamental misreading of Derrida's grammatology. Emphatically, Derrida does not idealistically reduce everything to language when he insists (in Of Grammatology) that 'there is no outside-text' (1974: 158): as has frequently been noted, the popularized translation of 'Il n'y a pas de hors-texte' as 'there is nothing outside the text' is both incorrect and misleading in that it suggests an ontological understanding of language (where language would, in theory, be capable of total description). Instead, Derrida's point is that 'what opens meaning and language is writing as the disappearance of natural presence' (Derrida 1974: 159), in the sense that language is a condition of legibility, even if it always renders its objects paradoxical and incomplete. Importantly, then, the term 'opens' indicates that Derrida does not claim that language is 'the exclusive or privileged faculty of experience' (Hansen 2000: 14), as Hansen's argument requires. Instead, Derrida's formulation insists simply that, insofar as there is meaning (i.e. signification, sense, an interpreted goal, etc.) this meaning is contingent on the instability and ambiguity inherent in language. Thus, it is resolutely not Derrida's belief that language determines bodily experience per se, but rather that it is the technology through which experience is registered as such, and that this registration reveals both language and experience as always-already simultaneously 
present and absent in their relation. For example, my digestive system might well behave extralinguistically, but my experience of it as a functional operation (i.e. a system that digests my food) is linguistic; I can say neither that my digestive system preexists, for me, its meaning (which would be to say that it pre-exists itself), nor that the meaning of my digestive system preexists it (because I can only know it insofar as I can experience it). ${ }^{\mathrm{vi}}$ For Derrida, the same is the case for technology.

Put simply, the object of Derrida's critique is not experience (as Hansen claims), but knowledge: to the extent that the machine appears in Derrida as a metaphor for technology itself, it does so as a metaphor, which is to say as a substitution for the (impossible) necessity of technology, for its paradoxical presence/absence. Indeed, this ambiguity is even exemplified in a passage from Derrida that Hansen cites in his argument. Consider the following:

A certain sort of question about the meaning and origin of writing precedes, or at least merges with, a certain type of question about the meaning and origin of technics. That is why the notion of technique can never simply clarify the notion of writing. (cited in Hansen 2000: 85)

For Hansen, this passage exemplifies the machine's 'foundation in différance' (2000: 85), a view which positions grammatology as an identifiable ontology. However, this neglects the crucial hesitation in Derrida's writing: in his parenthetical 'or at least merges with,' Derrida gestures to the paradoxical temporality at the core of deconstruction, the impossibility of answering questions of 'meaning and unknowability.' In Of Grammatology, this impossibility is figured as a trace (or 'arche-trace'), a mark that 'was never constituted except by a non-origin [...] which thus becomes the origin of the origin' and which cannot be marked by empiricism (Derrida 1974: 61). Clearly, then, Hansen's implication that Derrida submits technology to a structural logic only tells half of the story, and misses the explicitly strategic aspect of Derrida's writing: to the extent that Derrida positions writing as preceding technology, he does so keenly aware (as Spivak notes) that he is operating 'according to the very vocabulary of the thing he delimits' 
(Derrida, cited in Spivak 1974: xviii). Indeed, this is why the notion of technique can never simply clarify the notion of writing; they are all bound together in a paradoxical linguistic logic (a notion-ality?) that always performs something supplementary to its claims.

Thus, to say that technology is reduced by grammatology is problematic on two counts: firstly, it ignores this statement's congruence with grammatology on the point that technology can never be fully represented — can never be fully present—in language. Secondly, it assumes that such full presence is in fact possible, in the sense that language might reduce technology rather than ambiguously constitute it. Simply put, Hansen's claim that grammatology reduces the exteriority of technology rests on a translation of grammatology into a totalizing structural system of meaning. Moreover, this reduction allows Hansen to naturalize technology outside of language, while nonetheless operating its force within it: if technology is truly radically exterior to language in the way that Hansen indicates, how could it possibly interact with the linguistic paradigm that characterizes the type of meaning that Hansen requires?

Hansen is certainly aware of these quandaries, but believes they are symptomatic of a 'culturally ingrained logocentrism that compels us [...] to translate technological materiality into discourse' (2000: 52). In contrast, then, Hansen turns to Bourdieu's account of mimeticism to develop a notion of a bodily hermeneutic that avoids 'translation or delegation into language [by requiring us] to learn to use our mimetic bodily "sense" (Hansen 2000: 52). This 'practical mimesis' takes place below the threshold of knowledge as it is staged in representation, and thus yields embodied 'knowledge' that can 'only be experienced through mimetic reproduction, never through translation into language' (Hansen 2000: 52), a necessity that Bourdieu suggests is 'particularly clear in non-literate societies, where inherited knowledge can only survive in the incorporated state' (cited in Hansen 2000: 51) ${ }^{\text {vii }}$ For Hansen, then, developing this mimetic 
bodily sense is a promising method of unshackling bodily experience from the profoundly restrictive dependence on representation (and cognition) that grammatology imposes.

However, this raises the question: isn't cognition included in embodiment? That is, it is at least possible that the 'mimetic faculty' that Hansen suggests already exists as cognition, as the body's way of representing itself to itself. ${ }^{\text {viii }}$ Hansen's objection to this suggestion might be that embodiment remains subjected to representation, but this would neglect (as shown above) the profound avowal of that which is erased in representation. Moreover, to the extent that grammatology recognizes a materiality of language, does this not indicate the kind of sensory retraining that he is suggesting? It is a slippery point, but I would suggest that this is so not only because - as Hansen insists - there is a logic to the body that is external to language (which is certainly true, though to what extent the two might interact remains in question), but also because identifying the problematic of embodied knowledge as distinct from that of language depends on a (provisional, at least) separation of mind and body that has by now been so thoroughly and routinely deconstructed that, for most contemporary readers, the separation of the two cannot be sustained. In this sense, Hansen abstracts the body into a primordial blank slate, producing a normative 'body' that is not connected to any particular embodiment, thereby taking the body as a given. ${ }^{\mathrm{ix}}$

Thus, to the extent that Hansen critiques the (reductive) identities produced by representation, he is perfectly in agreement with a deconstructive approach. Where he differs is in the belief that we can intentionally develop faculties that are - and forever remainfundamentally foreign to intention, but that are still meaningful. If we were to really take seriously his call to develop a bodily sense that is not subject to language, then, we would have to do so without having set out, intentionally, to accomplish this. Not only is this impossible, but 
it is an impossibility that is structured according to the very paradoxical logic of language that Derrida’s grammatology writes.

Of course, Hansen is not unaware of this paradox. Indeed, the final pages of Embodying Technesis turn to Benjamin as a means of pointing 'beyond the impasse of technesis [by] refusing to collapse the technological real into representation and by linking it to embodiment' (Hansen 2000: 263). Again, though, this reinforces more than undermines Derrida's account. Moreover, how precisely we can 'make sense of technology's diffuse, amorphous corporeal impact without filtering it through language' (Hansen 2000: 263, emphasis added) remains underdeveloped in Hansen's text. Or rather, perhaps it is performatively overdeveloped, which is to say that Embodying Technesis performs a leap of faith — a leap into impossibility — that it cannot avow. What Hansen accomplishes, then, is not so much a movement beyond language to technology, but rather a re-staging of the dramatic and paradoxical ambivalence that language performs.

If Hansen's notion of technesis does not convincingly refute - or side-step — the textual logic of Derrida's grammatology, it nonetheless remains a powerful analytical tool for specifying the interaction of representation, embodiment, and technology. For Hansen, this interaction is embodiment, which is to say that he insists that "any system involving "information" requires an interpreter, and that interpreter is the material human body grounded in the wetware of our sensorimotor systems' (Lenoir 2004: xxiii). Importantly, then, Hansen mobilizes an affective understanding of embodiment that accords it both ontological and perceptual priority/precedence. For Hansen, the body exists in its affective dimension prior to its articulation in the senses; further, it actually serves as the frame through which these senses 
come to be understood as such. As Lenoir summarizes, in Hansen's account 'the affective body is the "glue" that underpins consciousness and connects it with subperceptual sensorimotor processes' (2004: xxiv).

Hansen's articulation of this pre-subjective affectivity, especially in the mature form that it takes in Bodies in Code, is considered in greater detail below. Here, I emphasize the relation of vision to embodiment that this perspective entails, and particularly how this relation is revealed in and through contemporary technologies. Understanding Hansen's account of vision will help to contextualize his views on perception in general, which in turn will elucidate the precise sense in which the body, for Hansen, exists as a unified field that precedes_logically, if not chronologically or developmentally — the differentiation of the senses (Hansen 2006a: 64). Simply put, Hansen understands vision to be a figuration of embodied process, rather than an abstract power that informs it: vision is not (strictly speaking) a medium, but is instead a technological extension of the medium of embodiment.

Hansen illustrates this through an analysis of Roberto Lazzarini’s installation skulls (2000, see images). First exhibited at the Whitney Museum of Modern Art, skulls consists in four sculpted skulls, each mounted at approximately eye-level in the centre of a different wall of a small, , clean, and bright four-walled room. ${ }^{\mathrm{x}}$ Lazzarini created the skulls by digitizing an actual skull as a two-dimensional digital image. After being subjected to an array of (two-dimensional) image editing techniques, the image is then ported to the simulated three-dimensional space of a computer-modelling program. In turn, the resulting model — or rather, the resulting digital image of a model — is outputted to a rapid prototyping machine that 're-sculpts' the skulls — threedimensionally_from resin, bone, and pigment (Lazzarini 2000). ${ }^{\mathrm{xi}}$ 
In effect, skulls translates literal and digitally imaged three-dimensionality into one another, but also combines two-dimensional and three-dimensional realities. This oscillation between materialities and dimensionalities 'creates an unsettling spatial paradox [wherein the skulls] appear to expand and contract as [the viewer's] vantage point shifts, suggesting something both static and moving' (Lazzarini 2000). As a result, skulls can never entirely be resolved in perspectival space in two senses: firstly, the 'proper' viewing perspective is different for all four skulls arrayed around the room, so that the visual solidity of one coincides with a liminal position in the others; secondly, and more importantly, because the skulls are modeled using two-dimensional distortion techniques the depth of the individual sculptural objects 'interferes with the illusionary resolution of perspectival distortion' (Hansen 2004: 202). As a result, the 'the perceptual experience of the work yields an oscillation or leveling of the figureground distinction' (Hansen 2004: 202).

For Hansen, this ambivalence forecloses the possibility of visually mastering the work: although skulls is visually perceived, the content of this perception is not visual per se in that it displays a logic that is fundamentally at odds with that of vision. In fact, Hansen argues that what is seen in skulls is not really a perception at all in the conventional sense, but rather a disjunction that exists between human perception and digital technologies. In this respect, we don't so much see the installation as we feel—affectively—the inaccessibility of its digital material to our senses. That is, skulls presents a 'realignment of human experience from the visual register of perception (be it in an "optical" or "haptic" mode) to a properly bodily register of affectivity in which vision, losing its long-standing predominance, becomes a mere trigger for a nonvisual haptic apprehension' (Hansen 2004: 209). Thus, although the installation does not afford 'a direct apprehension of an alien space that is digital, [it does yield a] bodily apprehension of just 
how radically alien the formal field of the computer is from the perspective of the phenomenal modes of embodied spatial experience' (Hansen 2004: 206). In so doing, skulls manifests the (for Hansen) radical exteriority of digital technology to the logic of vision, but also how visuality (which includes, for Hansen, figurations of the other senses) is shaped in terms of 'more visceral' bodily elements.

Importantly, then, Lazzarini's warped skulls institute a warped space that is sensibly felt by the viewer, even if only as a disjunction between digital materiality and the physical laws that we are accustomed to. The point is that 'the body continues to be the active framer of the image, even in a digital regime' (Lenoir 2004: xviii). That is, Hansen argues that the spatial disjunction experienced in skulls is situated in and as the viewer: rather than a gap between internal and external sensation, this disjunction is an interval within the viewer's body, a 'bodily spacing' that indicates the precedence of an embodied organism over its sensory perceptions. Put differently, by rendering the spatial activity of the participant's vision useless (since they are unable to delineate their distance from the skulls through conventional geometric perspective), skulls initiates a shift to an 'alternate mode of perception rooted in our bodily faculty of proprioception' (Hansen 2004: 203). In this way, the work functions by catalyzing an embodied sense of the skulls' form (i.e. an 'affective process of embodied form-giving') that creates a place within our bodies that, in its creation, gives us a 'sense of the "weirdness" of digital topology' (Hansen 2004: 203).

For Hansen, skulls is thus exemplary of the potential of new media art: rather than citing digitality as an abstract placeholder figured through arbitrary metaphors (i.e. the various visual associations that we have come to associate with cyberspace), skulls 'presents us with actual artifacts from the digital realm' (Hansen 2004: 204) that are not 'channeled through the 
coordinates of an image designed for interface with (human) vision' (Hansen 2004: 203). As a result, the installation acts as a 'cipher or index of a process fundamentally heterogeneous to our constitutive perceptual ratios' (Hansen 2004: 204): the experience of the piece takes place as an affective response in the spectator that correlates to the work's digital topology while nonetheless remaining radically discontinuous with it. In the experience of skulls (and other exemplary works of media art), Hansen believes that we can bodily access a material specificity of technology—or rather, we can appreciate the radicality of a particular technology's inaccessibility—without reducing it to language. (2004: 205).

It bears emphasizing that to the extent that this is the case, it is accomplished via a movement of vision into the body that Hansen describes under the auspices of the body's affective topology. With this in mind, consider as a counter-example the piece Sound (2001), a piano performance consisting of a combination of piano preparations, extended techniques, and fast playing with the piano's sustain pedal depressed. ${ }^{\text {xii }}$ First presented in the context of a contemporary music recital, Sound utilizes microphones that are placed inside the piano, routed through a computer featuring sound-processing software, and plugged into loudspeakers. Despite this setup, though, the computer is not powered on, so that the physical sound of the piano is in no way altered by the digital technology that is present: the piece is simply a piece for piano....and yet it isn't.

Somewhat predictably, audience members often hear effects generated by the microphone-speaker-computer setup when listening to Sound, despite no such effects being literally present. More remarkably, though, this tendency obtains even in the context of highly trained listeners, for whom the sound-world of the piece is by no means novel. Moreover, these skilled listeners—and I am not using the term 'skilled' ironically—are sometimes even able to 
specify particular effects: audience members attest to hearing various equalization filters (e.g. high-pass, shelving, and parametric), delays, and shifts in synthesized reverb and dynamics. In fact, I have anecdotally noticed that the more sophisticated a listener is - the more they are able to specify what they've heard in a given piece - the more likely they are to experience highly complex and specified hallucinations during Sound's performance. xiii $^{\text {in }}$

Sound is not a sonic hoax, because it does not ultimately deceive the listener's ears. That is, the sounds that the listener (mis)identifies as digitally produced are nonetheless audible and even properly identifiable, in the sense that the listener is able to specify (via the terminology of digital technology) the particular sounds that they are hearing. ${ }^{\text {xiv }}$ Moreover, it is plausible that the digital technologies represented on stage actually serve to increase the audibility of the nuances of the piece, because they signal a mastery of timbre that is often neglected in acoustic instruments (i.e. they emphasize the fact a single piano pitch consists in a series of frequencies). Rather than being a hoax, then, the technologies presented on-stage in Sound act as a rubric for the sound-world of the piece.

What is of interest here is how this rubric actually functions. Operationally, the technology (not) used in Sound is more familiar (i.e. more sensible) than the acoustic phenomena from which it was developed. In this sense, the piece employs a simulation wherein representations - the sounds of particular effects — are detached from any necessary attachment to their acoustic provenance. As a result, it is not only the case that the digital technologies offer a visual point of entry into the sound-world of the piece, but also that they offer a point of departure from the linear causality—-the instrumentality—of the acoustic instrument (i.e. the piano, as the sounding mechanism of a score or musical intention). In a mixed reality context such as that suggested by the technologies represented on stage, then, the physics of the 
performance - the question of what, materially, causes a given sonic event - subtly shifts into a kind of "pataphysics wherein the imaginary sonic reality precedes its cause. ${ }^{\mathrm{xv}}$ Simply put, the computer functions as an alibi for limitless representational manipulation, so that the listener accepts that the sonic events are not completely constrained by a recognizable causality. That is, the computer creates an illusion of a certain type of music-live electronic manipulation of an acoustic instrument - that presents itself as music without illusions. ${ }^{\text {xvi }}$

Indeed, this 'limitlessness' is the flip-side of the listeners' tendency to project specific technical manipulations onto the piece: listeners' (mis)recognition of the processing is frequently accompanied by questions about other aspects of Sound's sound-world. Often, these questions come from a lack of second-order identification of the phantom processes: for example, a phantom EQ might be heard as one that is regularly deployed in the program MaxMSP, which would lead to questions about other (phantom) manipulations that the listener did not recognize as being conventional in that programming environment. ${ }^{\text {xvii }}$ Thus, a series of questions are asked (e.g. 'Is another software program being run in parallel?' or 'Was that accomplished by misappropriating such and such object in Max?') that not only presume the event, but also understand it to be a technical fait accompli. Rather than creating disjunction in the listenerrather than causing them to question whether things are as they seem — these questions are couched not only in the certainty that the processing took place, but also in the assuredness that they took place as identifiable, predictable, and repeatable technical manipulations within the computer. With the presence of the computer, the de facto assumption is that anything that can be represented sonically to the listener can also be represented within the computer, and that with this representation comes a potential for manipulation that is virtually unconstrained. As Paul Théberge (among others) has noted, 'a computer is both a machine and a social relation' (212); 
in Sound, the machine-computer is extended through the technology of the piano, which empties it of its instrumentality to feed it back as a paradoxical relationality. Sound, then, is virtual music par excellence, where the boundlessness of the virtual is acted under the alibi of computer technology that it does not otherwise employ.

This is notable in the context of this essay because it is the opposite of what Hansen accounts in skulls. Whereas Hansen demonstrates that skulls renders techno-logic visceral because it cannot be represented by the senses, Sound offers a 'pure representation' of technology that captures viscerality in its exchange. In Sound, the boundlessness of the virtual is acted precisely through the way that it opens the senses to its 'pataphysics, to a willingness to accept seemingly unconstrained causality without giving up the notion of causality itself (that is, without leaving the realm of conventional representation). Thus, if skulls catalyzes a (disjunctive) perception of the grounding of vision in pre-sensory embodiment, Sound suggests that the reverse also takes place. That is, in Sound the affective body partakes in a logic of representation wherein 'the body itself' moves into the object of its senses, feeling'presensorily'-its profound complicity with the non-causal causality of grammatology. Simply put, the grounded and constrained physics of the body is excavated into a play of representation. Indeed, this understanding is coded into Hansen's claim — further discussed below—-that virtuality resides in and as analog subjectivity, which includes as its corollary the disarticulation of virtuality from digital technologies. That is, although virtuality has an affinity with digitality, it nonetheless 'stretches back to the proto-origin of the human' (2006a: $x$-xi). Put bluntly, the virtual is (for Hansen) the space into which technics externalizes the body. The difference with Sound, though, is that the body proper is not externalized, but rather translated (or re-embodied) into a visual representation. ${ }^{\text {xviii }}$ Moreover, this process feeds back to re-insist that the initial body 
is subject to representation: to the extent that the listener feels the piece, they do so within a logic that is suggested by its representations rather than via a spacing that would ground this logic. ${ }^{\text {xix }}$ To the extent that the body is externalized into virtual space, then, it is also always-already virtual. $^{\mathrm{xx}}$

This does not undermine Hansen's reading of skulls. However what Sound does demonstrate is the leap of faith that Hansen makes in order to move from his perceptually and cognitively based reading of skulls to his positing of the body as primordial (and thus precognitive and-conceptual). Without this leap, for example, we would be forced to ask why vision is not accorded the radicality that technology is? If vision takes place at an ontological level that is different from the embodiment that grounds it, doesn't this mean that there is a part of vision, however small, that is not accounted for in embodiment? As such, doesn't Hansen reduce vision to the affective logic of the body that he expounds? If so, what is accomplished in this reduction?

What I have attempted thus far is a simple re-contextualization of Hansen's thought: rather than accepting his cogent analyses as proof-positive of the structure of subjectivity that he advocates, I have demonstrated that his writing necessarily performs a gap between presence and absence that its content covers over. As a result, I have suggested that rather than an affective body preceding the senses, the two necessarily exist in tension with one another. However, in insisting on this tension I am not suggesting that affectivity is antecedent to the senses either, but am rather importuning the impossibility of establishing a hierarchy in their relation. Put differently, while Hansen's perspective cannot be unequivocally true in the way that he hopes, it nonetheless performs an important intervention into the potentially stagnant discourse of 
deconstruction: if contemporary theorists have become comfortable with the paradoxical play of presence and absence brought to the fore in deconstruction, Hansen's writing serves a decisive role in re-introducing the body as a site of discursive discomfort. Thus, if Derrida's work was necessitated by a historical context that presumed presence, Hansen writes in a time that has perhaps — at least with respect to Humanities scholarship — moved too far the other way.

With this in mind, I offer in what follows a closer consideration of Hansen's account of affectivity, presented in an effort to specify Hansen's 'organismic' construction of technological posthumanism as the twin presence of the manifold absences that have been made manifest in Humanities scholarship over the past forty years. Hansen's posthumanism is perhaps uniquely suited to articulate this perspective since, of the dominant strains of posthumanism that obtain in the discourse, Hansen's perspective is amongst the most avowedly humanist: whereas one might argue that Hayles, for example, insinuates humanist values into the ground of her claims for expanded understandings of embodiment, materiality, and meaning, Hansen restages these expansions within the internal spacing of presensory human affectivity. Accordingly, Hansen acknowledges that it is specifically human embodiment that 'takes on a truly unprecedented responsibility [at this particularly crucial moment in our coevolution with technology]: the responsibility of constraining and thereby specifying the process through which information “objects”—images, space, events—are actually generated' (2006a: 176). This distinction between Hansen and Hayles is crucial, because it relates directly to how value — broadly construed to include meaning, ethics, and politics—operates in the schema. For Hayles (as well as for related but less digitally oriented theorists such as Butler) value appears as an injunction to mean, so that the exciting possibility opened by new technologies is their affordance of new modes of represented individual agency; value is external in this reading, in the sense that it is a 
motivating principle of Hayles' thought. For Hansen, in contrast, value is produced via the body's internal spacing, so that what is exposed by virtual technologies is 'the violence exerted on bodily life by generic categories of social intelligibility and the politics of recognition' (Hansen 2006a: 147). Thus, if Hayles' posthumanism ultimately reinscribes the human, Hansen's does so doubly, but with a key difference inhering in how they position their intervention in the discourse of posthumanism: whereas Hayles figures her thought as unwinding embodiment outwards into intermediating machinic materialities (that themselves feed back to bodies), Hansen works in the inverse direction, folding new technologies—including new modes of perception—back into the primary tactility of embodied subjects. Hansen is not interested in new technologies for their potential to reconfigure what value is, but rather for their potential to reconfigure how value acts. ${ }^{\mathrm{xxi}}$

To grapple with this shift, it is first necessary to exfoliate the particular understanding of technology that is at the core of Hansen's thought, and which exists in contradistinction to the notion of technesis discussed above. Fundamentally, Hansen considers technology to be intimately bound up with human embodiment. Quite simply, Hansen argues that every technology exists in relation to human embodiment and speaks to 'the body's role as an “invariant," a fundamental access onto the world' (2006a: 26). While technologies may 'refunctionalize' (2006a: 26) the body, then, they do not institute any ontological shift that would threaten phenomenological accounts of embodiment. Instead, technicity is understood by Hansen to be a process of 'exteriorization.'

Importantly, though, Hansen does not consider this relation to exteriority to be something 'merely added on to some "natural" core of embodied life' (2006a: ix), but rather takes technicity to be 'a constitutive dimension of embodiment from the start' (2006a: $\mathrm{x}$ ). In this respect, he 
echoes Butler in registering a 'turn' at the core of our subjective relations, for Hansen hinging on technology: technologies extend our interface with the environment, but the reconfiguration that this performs points back to a body as its source. In this sense, then, a 'technical element [...] has always inhabited and mediated our embodied coupling with the world' (Hansen 2006a: 26). While Butler understands this coupling to be the continual and reiterative process of subject formation, though, Hansen understands it as the exteriorization of an anterior subjectivity: since Hansen takes the body to be 'invariant,' he is able to mobilize a topological analysis of it. In so doing, he figures a gap that is fundamentally different from the deconstructive gap: where the former is a spatial separation, the latter is both a performative gap and a dis-identification (hence différance's etymology in both difference and differment).

What is notable in this configuration is the conflation of technical and embodied reality that it enacts. Simply put, the distinction between virtual reality and so-called flesh reality is effaced, for Hansen, so that 'all reality is "mixed reality" (2006a: 6). In short, "there can be no difference in kind demarcating virtual reality (in its narrow, technicist sense) from the rest of experience' (Hansen 2006a: 6), because all experience pertains first to an embodied subject. As such, virtual reality is not so much something that is produced by technology as it is a 'biologically grounded adaptation to the newly acquired technological extensions provided by new media' (Lenoir 2004: xxiv). Virtuality, then, is not only interpreted by analog bodies, but is actually included in the constitution of these bodies as such.

In this context, Hansen insists on the cultural significance of virtual reality as 'our culture's privileged pathway for [...] exposing the technical element that lies at the heart of embodiment' (Hansen 2006a: 15): paradoxically, the value of virtual reality (again, in its narrow sense) is not found in the purported new freedoms that it offers, but rather in the way that its 
physical latitudes lay bare 'the enabling constraints of the body' (Hansen 2006a: 15). Here again, then, it is precisely because technics is included within a primordial notion of embodiment that we can comprehend virtual reality as a reality at all, which is to say as having enactive capacities rather than simply representational or simulational ones. In a sense, then, Hansen is simply staging a performance of deconstruction in and as embodiment.

In this context, Hansen argues that mixed reality is a transcendental condition for human experience. That is, mixed reality designates an "originary" coupling of the human and the technical' that grounds experience as such, and which 'can only be known through its effects' (Hansen 2006a: 9); while new technologies, specific historical realities, and evolved biologies all play a part in determining modes and meanings of perception that are absolutely unique to a given individual, the fact of human perception itself — or human 'information processing,' as Hansen sometimes terms it—nonetheless grounds this specificity. Put simply, while information processing may radically transform the instance of embodiment that it points to, the fact that it must be directed at an embodied reality always remains. Moreover, Hansen's conceptualization of 'mixed reality' includes the assertion that this works both ways, so that an instance of embodiment—a human, for example—necessarily operates relative to its surroundings. This omnipresent bivalent coupling, then, is precisely what Hansen designates with the term mixed reality, effecting a passage 'from the axiom that all virtual reality is mixed reality to the more general axiom that all reality is mixed reality' (2006a: 5).

This persistence of an embodied relation to technics (which is to say, of embodiment) is the sense in which mixed reality is both transcendental and omnipresent. Moreover, this status means that the effect of technological innovation is not to create new realities, but rather to alter the relationship between our perceptual apparatuses and the techno-embodied reality that 
grounds them: incompatible strata of reality, for example, are not incompatible with our conventional perceptions because they are inaccessibly distant, for Hansen, but rather because they are too close, they are the ground of perception. In this sense, contemporary technologies create different points of contact — quantitatively different in scope, but to such an extent that a qualitative difference emerges- between humans and non-humans, that thereby shift the ground of perception to give the effect of new strata of reality. In addition, then, Hansen does not accept the suggestion that fundamentally new realities emerge from the intermediation of humans and machines: while, epistemologically, Hansen characterizes the historical evolution of humans technogenetically, he nonetheless insists on an ahistorical mechanism underlying this process that grounds epistemological accounts of subject positions in an ontology of primary subjectivity. Put simply, the oft-cited extra-discursive characters of technology and embodiment are, for Hansen, specifically pre-discursive. Relative to much of posthuman discourse, then, Hansen's position performs the crucial shift of acknowledging the particular worldview that (for him) undergirds the entrance of humans and technology into a joint discourse.

In this respect our 'age of total technical mediation' (Hansen 2006a: 12) is, for Hansen, the age where the mixed-ness of reality is exposed. That is, reality has always been a mixture of virtuality and actuality, but contemporary technologies dramatize this to an unprecedented extent. In Hansen's often tenebrous prose, the present historico-technical moment is thus dubbed the 'becoming-empirical [...] of mixed reality as the transcendental-empirical' (2006a: 9), such that contemporary technologies empirically manifest 'the condition for the empirical as such' (2006a: 9). Paradoxically, then, Hansen insists that the disembodying tendencies of digital technologies serve to make perceptible the embodied reality—which includes technicity—-that 
they depend on. As such, the shift to mixed reality effected in and by contemporary technoculture is a paradigmatic, rather than ontological, one.

If Hansen insists that mixed reality transcends local technological conditions, this is not to diminish the importance of the latter. Indeed, by making mixed reality widely perceptible digital technologies bring 'an opportunity to revalue the meaning and role accorded the body within the accepted conceptual frameworks of our philosophical tradition' (Hansen 2006a: 7). Thus, Hansen notes that today's exemplary mixed reality situations - 'interrupting a meeting to get data from a digital database, comparing a two-dimensional architectural drawing with a realtime three-dimensional visualization, acquiring an image of oneself through the social prosthesis of common sense that is contemporary television' (Hansen 2006a: 8) —are not intended to produce an 'immersive' experience, in the sense of simulating reality. Instead - as we saw in his reading of skulls-Hansen argues that these situations each utilize the "capacity of our embodied form of life to create reality through motor activity' (2006a: 8). Prior to the exposure of mixed reality through digital technologies, this capacity was entirely unremarkable. Thus, by moving perceptual experience beyond a single experiential frame, the question (cited at the beginning of this essay) of 'what makes [...] passage from one realm to another so seamless' (2006a: 8) can be asked.

In the context of this essay, the point is that Hansen's understanding of embodiment and technicity necessarily re-conceptualizes the body in a way that avows its contingency while still retaining its primacy as the ground in which this conflation takes place. I have already argued that this understanding is more complicit with deconstruction than Hansen suggests, but it bears noting that what is thus at stake is not only a pre-linguistic body, but also an articulation of the 
'spacing' that comprises an organism's embodiment. In this, Hansen promotes an understanding of the body that is based in its operational perspective. .xii $^{\text {. }}$

The logic of this operational perspective is explicitly drawn from contemporary autopoietic theories of cognition. In particular, the 'enactive' approach promulgated by Varela is apt, as it is based on situated, embodied agents. As Varela explains, this approach to cognition 'comprises two complementary aspects: (1) the ongoing coupling of the cognitive agent $[\ldots]$ that is fundamentally mediated by sensorimotor activities; and (2) the autonomous activities of the agent whose identity is based on emerging, endogenous configurations (or self-organizing patterns) of neuronal activity' (Varela 1999: 272). For Hansen, then, considering the body in this way offers the opportunity to consider it as a bounded entity that is coupled with technics, without falling into the reductive binary logic of (non)identity: the body is coupled with technics in precisely the sense that all life "necessarily involves a "structural coupling" of an organism and an environment' (Hansen 2004: 299). In this approach it is movement, rather than identity, that 'takes center stage as the act which $[\ldots]$ correlates, articulates, or mediates between space and time' (Hansen 2006b: 1208). From this, Hansen turns to operationality to provide a means of articulating the body as an 'originary condition of real experience' (2006a: 9).

And yet, (once again) Hansen's insistence on the term 'origin' bears further reflection: what is the body's 'originary technicity' if not precisely an example of 'origin-heterogeneous,' as described by Derrida (1989: 107-108)? Indeed, in showing that the body's movement 'speaks to a modality of life that lies between and conjoins — that composes—space and time' (2006b: 1211), Hansen would seem to be reinforcing the Derridean truism that every identity—in fact, every term — is necessarily infected by others that it cannot register: technics itself, in Hansen, is placed 'neither on the side of consciousness, nor on the side of matter, but rather as their 
mediation, the transduction to which they owe both their coupling and their proper existence' (2006b: 1211). I raise this concern again because Hansen's response to this critique shifts in Bodies in Code: whereas Embodying Technesis focuses on specifying what, precisely, technology is, Bodies in Code's operational emphasis attempts instead to specify how embodiment—as the coupling of a body and technicity—produces the effects it does. That is, Hansen becomes less interested in what humans and their embodiments categorically are than what is entailed by these constructions. In this light, claiming an originary status for the (subjective) body amounts to naming it as an enabling constraint for the enactive approach that Hansen undertakes: whereas a deconstructive sensibility prevents us from agreeing with the definition of a pre-subjective body that Hansen mounts in Embodying Technesis, Hansen's shift in emphasis might permit him to side-step these concerns because he is no longer delineating a fully present body per se.

Indeed, Cary Wolfe has convincingly argued for a view of systems theory (specifically that of Luhmann) as the 'reconstruction of deconstruction' (Luhmann, cited in Wolfe 2010: 8), noting that Derridean deconstruction and Luhmann's systems theory each approach a similar problem from opposite directions. Specifically, both approaches

make difference their basic category, both temporalize difference and reconstruct meaning as a temporally organized context of displacement and deferment. Both regard their fundamental operation (i.e., writing or communication, respectively) as an independent process that constitutes the subject rather than lets itself by constituted by it. (Schwanitz, cited in Wolfe 2010: 13)

This is not to efface the difference between the two approaches-Wolfe argues that systems theory links deconstructive dynamics 'to their biological, social, and historical conditions of emergence and transformation' (Wolfe 2010: 8) — but only to point out that Derrida is not necessarily opposed to the operational logic that Hansen espouses. 
However, this line of argumentation does not ultimately obtain in Hansen's case, because he continually extends the import of his thought beyond this constraint, which is to say beyond a deconstructive reading that would understand embodiment's operational 'originality to also indicate its non-originality. Specifically, Hansen's shift towards an analysis of effects depends on the possibility of extra-linguistic meaning that it moves away from, so that this disavowal of grammatology might be considered a 'meta' enabling constraint that allows constraint to mean something. In this context, though, one wonders if the term 'origin' doesn't thus function as a rhetorical bivalence in the text, at once indicating Hansen's insistence on following through on a specific, organismically organized, account of posthumanism, while simultaneously acknowledging — rhetorically — the limitations of doing so. Whether this is a conscious tactic on Hansen's part is, perhaps, irrelevant: instead, the ambivalent rhetoric of the text points to an opening in it that suspends, if not extinguishes, a deconstructive line of critique.

Indeed, the operational emphasis that becomes increasingly prominent in Hansen's work moves his thought ever-closer to the linguistic ambivalence that he continues to hold it in contradistinction to. Perhaps most telling, in this respect, is his conception of 'bodies in code' as a designation of the way that embodiment 'is necessarily distributed beyond the skin in the context of contemporary technics' (2006a: x): a body in code is 'a body submitted to and constituted by an unavoidable and empowering technical deterritorialization' (Hansen 2006a: 20). As with mixed reality, all bodies are 'bodies in code' because coding indicates the (technical) process through which bodies are coupled with their environment.

Here again, though, the ambivalence of this deterritorialization is crucial, because its 'technical' aspect indicates the constraining role that technology plays in addition to its more regularly cited extending capacities. Indeed, as Hayles notes, this insistence on the constraints 
that remain active in digital bodies is at the heart of one of Hansen's significant points of divergence from Deleuze, his frequent interlocutor. Summarizing Hansen's argument, Hayles notes that Deleuze and Guattari serve their own philosophical commitments at the expense of reality, doing away with all constraints whatever by refusing to recognize the constraints built into self-organization when it takes place in a biological domain (2001: 155). In contrast, Hansen suggests bodies in code as a means to understand these constraints not only as enabling individual embodiments, but also as part and parcel of the complexity—in the full, evolutionary, sense of the term-from which emerges the new organizations and distributions of the senses that suggest technology's importance in the first place.

Through coded interactions with the environment, then, the body takes on an agency that is at once constrained and distributed. To elucidate how this is the case, Hansen refers to Merleau-Ponty's distinction between the 'body schema' and the 'body image,' which each offer a mutually exclusive way of conceptualizing the body: while the latter pertains to an apprehension of the body as an external object, the former privileges the (autopoietic) operational perspective that Hansen suggests is primary (Hansen 2006a: 39). Importantly, Hansen emphasizes that 'body image' is somewhat of a misnomer, as his argumentation (if not his argument, per se) hinges on its referring to something 'much richer $[\ldots]$ than a mere representation' (2006a: 133), acting instead as the object of intentional consciousness such that to the extent that we apprehend ourselves, we do so through a body image. ${ }^{x i i i}$ In contrast, the body schema refers to that which grounds experience as such, in the sense that it refers to the particular configuration of the body through which phenomena are made sensible. Put differently, the body image emanates from the body, extending it, whereas the body schema is 'a kind of infraempirical or sensible-transcendental basis for intentional operation' (Hansen 2006: 
39). While both refer to the body, then, they do so from 'opposite sides of the intentional relation [such that the body schema involves] an extra-intentional operation carried out prior to or outside of intentional awareness' (Gallagher, cited in Hansen 2006: 39).

And yet, while the body image and body schema do not overlap, they are also not of equal ontological importance for Hansen. That is, the operational perspective of the body schema means that, by definition, it relates to its environment: here again, Hansen's autopoietic conformation dictates that organisms react to environmental perturbations by modifying themselves in a way that preserves the distinction between their identity and the environment such that an autopoietic system is one that "continuously produces the components that specify it, while at the same time realizing it [i.e. the system] as a concrete unity in space and time [that] makes the network of production of components possible' (Varela 1992: 5). As an autopoietic system, then, the body schema includes the technics of the body image as the process through which it is exteriorized such that, in an important sense, the body image derives from the body schema. Thus, Hansen's understanding aligns with Varela's observation that reproduction 'must be considered as an added complexification superimposed on $[\ldots]$ an autopoietic unity, $[\ldots$ because] only when there is an identity can a unit reproduce' (Varela 1992: 6). The point for Hansen, again, is that the separation of the body from itself that takes place as the body image requires a pre-existing body that is identifiable in its own right. Here again, then, Hansen's departure from theorists such as Hayles is marked: for Hayles, the body schema would intersect with the body image according to her revised version of the semiotic square (see Hayles 1999: chapter ten), and thus remain within the realm of signification as such; for Hansen, the body image feeds back to construct novel points and means of access to the body schema, but does not challenge the latter's ontological priority. 
If I have shown that Hansen only tells half of the story, his organismic construction of technological posthumanism nonetheless remains an important specification of embodiment. Thus, the important thing to note is how Hansen has shifted the mark: while he has successfully articulated embodiment from an operational perspective, it is not clear how the bounds of embodiment are delineated except from an anthropocentric perspective that is constructed linguistically. That is, Hansen succeeds in accounting for technology's relation to the human sensorium, but in so doing sets aside the question of how this sensorium accrues an economy of meaning beyond simply maintaining its operational integrity.

With this in mind, I conclude this essay by considering the most explicitly political moment in Hansen's œuvre to date, chapter three of Bodies in Code (titled 'digitizing the racialized body, or the politics of common impropriety'), wherein Hansen argues that all humans are bound by a common impropriety that can be understood as a form of resistance to the reductive classification of people relative to categories of social visibility. ${ }^{\text {xxiv }}$ In particular, Hansen's analysis of 'Internet passing, ${ }^{\mathrm{xxv}}$ is illustrative of the pure body-in-code: because online self-invention yields an identity that is 'an imitation of an imitation [i.e. an imitation of culturally sanctioned signifiers]' these identities are 'purely disembodied simulacr[a]' (Hansen 2006a: 146). Precisely because of this status, Hansen argues that (for example) in the case of racialization 'a certain indetermination in the correlation between racialization and the image [is introduced, suspending] the "overdetermination" of the black body "from without" and thereby position[ing] the image as a static fixation of individuation' (2006a: 157). In short, Internet passing catalyzes an experience of failed interpellation, of an incongruity with oneself that is definitive of affectivity (that is, of primary embodiment as the grounding space, or 'spacing,' of 
perception). Thus, as Jennifer Gonzalez notes, Hansen presents a pedagogical vision of cyberspace wherein the transcendence of visibility teaches those who are engaged in online passing the 'bankruptcy of categories of identity' (Gonzalez 2009: 40).

The political dimension of Hansen's reading of the digital thus obtains in the fact that 'online interpellation submits everyone [...] to the condition of having to pass; the generalization of the condition means in effect that the resulting abjection of the lived body from the space of intelligibility (visibility) can no longer be limited to certain subjects, but rather becomes a problem for all' (Hansen 2006a: 147). And this, Hansen argues, points to the shortcomings of existing theories of interpellation: in Butler, for example, performative practices 'function by making the bodily residue [or representation] culturally intelligible' (Hansen 2006a: 146) and thereby build the radicality of embodiment into the scene of interpellation and thus deny it any standing outside the interpellative act. By contrast, the shared experience of Internet passing means that

we all must live the erasure of our lived bodies, [so that] what is most significant about the transcendence of visibility in online interpellation is less the possibility it affords for new modes of represented agency than its exposure of the violence exerted on bodily life by generic categories of social intelligibility and by the politics of recognition - identity politics - that it subtends. (2006a: 147)

In short, Internet passing does not so much open new avenues for self-expression, but rather rearticulates the bodily constraints that condition such expression in the first place.

Clearly, Hansen's analysis of Internet passing re-stages his argument against ‘linguistic reduction' in a political dimension. Here again, then, it merits note that the meaning that Hansen ascribes to this politics remains contingent on the (representational) process of meaningformation that he seeks to subjugate. However, we (like Hansen) can further specify this objection in its political aspect by considering his assertion that the digital makes intelligibility 'a problem for all.' Bypassing the obvious objection that would insist that, in fact, access to the 
Internet is not uniform or ubiquitous but is instead subject to its own complex social economy, ${ }^{\text {xxi }}$ we might ask what the term 'problem' means in this instance. That is, why does the body require this linguistic intelligibility such that it constitutes a problematic in the first place? In fact, given Hansen's larger project of freeing embodiment from linguistic interpretation, it would seem that just the opposite would be desirable in a bodily economy: to the extent that bodily specificity is reduced by technesis, it is not clear why this entrance into discourse - the condition of intelligibility - is politically desirable. That is, what mechanism (other than language) allows bodily concerns to migrate from the level of a techno-biological organism to that of a political organism without abstracting the contents of these strata into the logic of the body? In short, if an operational perspective constructs an organism in relation to its environment, how is the material specificity of that environment registered in its own right (i.e. as an extra-linguistic radical exteriority) while simultaneously being related to its constitutive organisms in their own right? That is, how do we register the material specificity of performativity, since it is clear that "not all forms of performance are equal, nor do they have equal effects' (Gonzalez 2009: 40). In the context of grammatology, this paradox is recognized to be constitutively irresolvable, and is acknowledged through the (hyper)mediating role afforded arche-writing. If Hansen shifts the site of this mediating role to the practices of bodies, though, it is not clear how inter-subjective and inter-strata political agencies can take hold without abstracting bodies into a discourse that (according to Hansen) does not register their specificity.

Further, we can conclude that the embodied excess to social intelligibility that Hansen explicates robs that intelligibility of that which makes it, literally, desirable. That is, if the conventional engine of interpellation is desire (which is predicated on a fundamental and radical lack that is articulated in and as the linguistic dimension), then the politics of Hansen's 
construction of posthumanism comes to its crux: on one hand, Hansen cannot follow Deleuze and Guattari (for example) in re-figuring desire as a line of flight that attaches to real objects, because this would preclude the techno-biological constraints that ground affectivity and that motivated his intervention in the first place; on the other hand, Hansen cannot maintain these constraints without invoking a notion of desire predicated on a lack that is linguistically inscribed by the Law. In the absence of either perspective, it remains unclear how political agency can come to be registered as a problem in the first place.

Thus, the politics of Hansen's organismic construction of technological posthumanism do not spring from the primordial subjectivity that he claims, but rather from the claiming itself: in the case of political agency, Hansen's writing performs the wrangling that has come to characterize the relation between the discourses of desire alluded to above. Indeed, this points to a broader observation about Hansen's understanding of affectivity, one that points back to the problem that this essay (and Hansen's theoretical œuvre) started with: in figuring a prediscursive body, Hansen in fact figures the discursive rent between technologists and cultural theorists that he seeks to address: precisely because he fails to take the discourse of technology beyond the pale of linguistic analysis, Hansen succeeds in articulating the necessity of continuing to think deconstruction in its most radical dimensions. ${ }^{\text {xvii }}$ That is, the rifts opened by Hansen's insistence on the primacy of affectivity remind us that the categories that language produces (such as race and gender, in the case of Internet passing) cannot simply be 'moved beyond,' because they are not properties of individuals but rather 'relations of public encounter' (Gonzalez 2009: 56). In this, a paradox takes hold: precisely because theoretical concerns do, necessarily, subjugate practical ones with respect to generating a meaningful understanding of posthumanity, they themselves are also subjugated by a profound co-implication of practice and 
research that precludes the possibility of either practice or theory keeping what it wins from the other. This paradox is that of deconstruction, and is precisely what is foreclosed by the misreading of Derrida that allows Hansen to clear the ground he then claims. By showing the ambivalence that grounds Hansen's thought, then, I hope to reveal the 'leaps of faith' into sensibility that redouble linguistic contingency under the auspices of eliminating it.

But what, in closing, does attending to the radicality of this position mean? With respect to the question of human-technology relations, it suggests that efforts to articulate posthumanism as an overcoming of deconstruction are doomed both to reify deconstruction as an opposition to embodiment and to recapitulate the very errors that have been patiently unearthed by deconstructive approaches at least since the publication of Grammatology. More generally, this challenge entails accepting the final undecidability of any signifying instance, so that there is a very real sense in which the question cannot be answered coherently. And yet, the challenge that this question implies - a demand to act responsibly, in the full sense of the term - is nonetheless convincingly met precisely because the question remains unanswerable, in the sense that it constructs posthumanism in a way that refuses the sedimentation of a unified discourse.

\footnotetext{
i 'Posthumanism' is different than 'transhumanism': transhumanism advocates a narrative of technological progressivism predicated on extending the capacities of human bodies; posthumanism, by contrast, is a much more variegated - and contested — discourse, tending to focus on the problematic of human/non-human relations. The 'post' of posthumanism as it is used here, then, names both a contemporary historical moment in which technical, medial, informatic and economic networks make it increasingly impossible to ignore Foucault's observation that 'humanism is its own dogma' (Wolfe 2010: xiv), as well as an anteriority that is the 'embodiment and embeddedness of the human being' in biological and technical worlds (Wolfe 2010: xv).

ii Hansen's work has garnered significant and sustained attention since the publication of New Philosophy for New Media, particularly in the North American vein of Media Studies and in emerging discourses of posthumanism. Compelling in its own right, Hansen's work is also a valuable site of inquiry because it combines frequently cited theories of affect and systems
} 
theory, each of which have been highly influential in discourses of posthumanism (as well as in the parent disciplines that posthumanism draws upon).

iii Hansen uses 'translation' in Latour's sense, as delineated in (Latour 1987: 132-144).

${ }^{\text {iv }}$ In this essay, I use the term representation in the broad sense indicated by Hansen, where he notes that 'by representationalist approach [he means] any approach that legitimizes representation as its frame of reference, whether for ends either affirmative or critical, positivist or deconstructive' (Hansen 2000: 4)

${ }^{v}$ For example, Hansen argues that systems theory functions 'by bracketing out all constraint the real might impose [on a system]' (2000: 80) such that materiality 'receives a purely abstract determination as that which resists translation per se' (2000: 79). Similarly, he accuses cultural studies of being 'restricted to the effects [technology] has on our capacity [...] to represent ourselves to ourselves, [...so that] whatever exteriority is thereby broached [can only be a] point of resistance internal to the representational space of thought' (2000: 78).

${ }^{v i}$ To be clear, the Derridean claim is not that all technical apparatuses partake of language's instability and ambiguity, but rather that our knowledge of them does (and that they come to be, for us, only through becoming objects of knowledge). However, the inverse is also true in that Derridean claims about language are predicated on language's not being understood as a system that is closed off from the operations of technics. Thus, the issue is not whether biological processes can operate independent of language, but rather that extrapolating these processes into an observational register (or a predictive or categorical one, for that matter) in order to delve into their meaning is not a neutral endeavour: understanding digestion as a digestive process, rather than as a random or even stochastic set of events, necessarily presumes a frame of reference (i.e. an individual, or a part of an individual) that is privileged linguistically.

${ }^{\text {vii }}$ Further to this, Bourdieu notes that "what is "learned by the body" is not something that one has, like knowledge that can be brandished, but something that one is' (cited in Hansen 2000: 51).

${ }^{\text {viii }}$ Hansen gestures towards this question in his detailed consideration of Merleau-Ponty's écart, through which Merleau-Ponty describes the flesh as the 'intertwining [and reversibility] of the sensate and the sensible [...that] directly problematizes the concept of intentionality' (Flynn 2008). However, Hansen maintains that, because the écart occupies the 'cusp between the biological and the psychic prior to their actual differentiation' (Hansen 2006a: 61), embodied alterity is 'a primary condition of the being of the body' (2006a: 74). In short, Hansen folds Merleau-Ponty's understanding of the flesh into his own concept of the primordial body. ix Jennifer Gonzalez notes that Hansen turns to Agamben 'to argue for digital media's potential to produce the conditions for the emergence of an identityless, subjectless singularity' (Gonzalez 2009: 47-48).

${ }^{x}$ My account of the literal material of skulls draws heavily from Hansen's description; see (Hansen 2004: 196-205).

xi 'Rapid-prototyping' describes a process wherein digitally produced image-models are rendered as physical objects. Variations of the technology are frequently used in manufacturing to quickly produce physical prototypes of computer-generated blueprints, where the latter are often drawn in computer aided design (CAD) programs such as QCad, ArchiCAD, and AutoCAD.

xii Sound is un-scored and site-specific, and has been adapted and re-appropriated for various instruments and settings. In every iteration, the compositional emphasis is on achieving the 
'pataphysical quality discussed below, rather than on acting a prescribed aesthetic or formal program.

xiii These listener accounts are (admittedly) anecdotal, and were not collected via any particular methodology. However, I would argue that this shortcoming does not impact the argument at hand: since Sound is discussed here in its conceptual — rather than aural — particularity, any reader who doubts the veracity of this account is welcome to take the discussion in the spirit of a 'thought-experiment' (i.e. 'if one were to be able to stage a piece that accomplished what is claimed for Sound, what would this mean?').

${ }^{\text {xiv }}$ For example, a listener who attests to hearing a low-shelf filter is saying that they hear a preponderance of frequencies that are higher than a certain pitch. The observation is correct, even if the reason attributed to it is not.

${ }^{x v}$ 'Pataphysics is a term coined by the French writer Alfred Jarry that means, roughly, 'the science of imaginary solutions.' The inclusion of the apostrophe at the beginning of the word 'was mandated by Jarry to avoid physical puns, [including] 'patte à physique' (leg of physics)' (Hiebert 2008: 121). As it is used here, the term also relates to Ted Hiebert's extrapolation of Jarry via the notion of 'pataperception, which "might be defined as "the observation of imaginary appearances"، (Hiebert 2008: 121).

${ }^{x v i}$ That is, the seemingly unbounded possibilities of live electronics obsolesce illusion, in the sense that they perform a claim to technical overcoming in place of the conventional sleight of hand that is implied in an acoustic setting.

xvii 'EQ' (short for equalization) refers to frequency-specific amplitude modulation, allowing the listener to emphasize the treble, mid, or bass ranges of a sound. 'MaxMSP' is a visual programming language that is commonly used for audio processing (though it also includes multimedia functionality), and includes EQ as a very small and basic part of its robust capabilities. The software is designed to be highly modular, with most programs (or 'patches') made by arranging and connecting 'objects' (which each have a specific function) within a twodimensional visual canvas. An explanatory video is available from the Cycling ' 74 website at http://cycling74.com/products/maxmspjitter/

${ }^{x v i i i}$ Or rather, the body is both externalized and not; Sound emphasizes the latter-which is the sense in which the latter takes place-but it nonetheless remains in tension with the former (vis $\grave{a}$ vis the discussion of deconstruction offered above).

${ }^{x i x}$ Importantly, this would be the case even without the computer technologies being present on stage, as the same logic applies to both the physical piano and the practical and conceptual architecture that binds the piece (i.e. that coalesces it as a unified object of study). In Sound, then, this process is simply desublimated.

${ }^{\mathrm{xx}}$ As suggested above and re-iterated below, this perspective's departure from Hansen is subtle, and occurs via the degree of strength accorded the deconstructive 'always-already.' For Hansen, this 'always-already' is a soft claim that pertains to representation only, rather than to the real as such.

${ }^{x x i}$ This opposition between Hayles and Hansen is amplified by being described, and is not intended to wholly contain the relation between the two. Instead, I am simply gesturing towards the implications of Hansen's insistence on the body's pre-discursive (as opposed to extradiscursive) status.

xxii This rendering of embodiment is implicitly underwritten by a cognitive theory of conceptual integration called 'double-scope blending.' In essence, this theory argues that humans are the 
only species capable of thinking and feeling beyond the scale of their biological configuration, and that this is accomplished through the ability to use our human scale as a scaffold ('a cognitively congenial basis') from which to reach out, manage, manipulate, transform, develop, and handle vast conceptual networks. 'These new human-scale blends become second nature for us, and blending is recursive: packed, human-scale blends become inputs to new networks [so that] what was once beyond human scale is now packed to human scale' (Turner 2009). In this way, double-scope blending suggests that 'basic structures already present in our sensory-motor processing can be recruited for abstract thought without presupposing separate systems allegedly unrelated to our bodily engagement with our environment'(Johnson 2009). In short, we are organismically configured to produce representations, but these representations remain grounded in our operations as a biological organism. It bears noting that double-scope blending has faced significant criticism: the 'problem' of how we integrate alternate scales can only be framed as such through a prior disarticulation of our cognition from our biology. If this is the case, though, then it would imply an emergence of cultural bodies - bodies whose reproduction takes place via a-genetic means - that, in turn, deconstructs the biological primacy that double-scope blending assumes.

xxiii This insistence points to a separate line of argument - most notably in New Philosophy for New Media - wherein Hansen takes issue with Deleuze's reading of the image in Bergson.

xxiv The following discussion, admittedly, raises more issues than an essay of this scope can adequately address. I include it in order to emphasize the tangible ramifications for the critique of Hansen that I have mounted, and to highlight the extent to which narrations of humantechnology coupling are complexly entangled with what the coupling yields.

xxv 'Internet passing' consists in passing oneself off as something/someone other than oneself online. For example, a man may 'pass himself' as a woman in an Internet chat-room.

${ }^{x x v i}$ Not only is the Internet not universally accessible, but when it is accessed it is not done so through uniform technological constraints, and this heterogeneity does not always parallel socioeconomic striations. Simply put, the materiality of the Internet has its own historical specifications, so that Jodi Dean has argued that 'while the Internet may indeed provide one site for democratic politics, it does not constitute a public sphere (particularly in the Habermasian sense of equal access and homogeneous participation)' (summarized in Gonzalez 2009: 60). ${ }^{x x v i i}$ In addition to the brief explication offered below, this challenge is also one of comportment. That is, if I have taken some pains to insist that Hansen hasn't simply misread Derrida but actually performs the ambivalence that deconstruction diagnoses, this is partially in order to buttress my argument against the notion that I am trying to execute a conservative gesture of 'taking Hansen back to Derrida.' To think deconstruction in its full radicality would involve, equally, a sense of deconstruction moving forward through Hansen; the renewed urgency that Hansen lends the discourse is, after all, no small matter when one acknowledges that Derridean deconstruction - like any discourse - morphs, coalesces, accelerates, and slows according to forces in addition to those of reason. 


\section{Works Cited}

Agamben, G. (2009) What Is an Apparatus? And Other Essays. Stanford, CA: Stanford University Press.

Barad, K. (1998) 'Getting Real: Technoscientific Practices and the Materialization of Reality,' differences: A Journal of Feminist Cultural Studies 10 (2): 87-128.

Derrida, J. (1974) Of Grammatology. Baltimore: Johns Hopkins University Press. (1989) Of Spirit: Heidegger and the Question of Technology. Chicago, IL: University of Chicago Press.

Flynn, B. (2008) 'Maurice Merleau-Ponty,' The Stanford Encyclopedia of Philosophy. http://plato.stanford.edu/archives/fall2008/entries/merleau-ponty/

Gonzalez, J. (2009) 'The Face and the Public: Race, Secrecy, and Digital Art Practices,' Camera Obscura 7024 (1): 36-65.

Hansen, M. B. N. (2000) Embodying Technesis: Technology Beyond Writing, Studies in Literature and Science. Ann Arbor: The University of Michigan Press.

- (2004) New Philosophy for New Media. Cambridge, Massuchusetts: MIT Press. (2006a) Bodies in Code: Interfaces with Digital Media. New York: Routledge. (2006b) 'Media Theory,' Theory, Culture and Society 23 (2/3): 297-396. (2006c) 'Movement and Memory: Intuition as Virtualization in Gps Art,' MLN 120: 1206-25.

Hayles, N. K. (1999) How We Became Posthuman: Virtual Bodies in Cybernetics, Literature, and Informatics. Chicago: University of Chicago Press. (2000) 'Clearing the Ground (Foreword),' in Embodying Technesis: Technology Beyond Writing. Ann Arbor: The University of Michigan Press.

(2001) 'Desiring Agency: Limiting Metaphors and Enabling Constraints in Dawkins and Deleuze/Guattari,' SubStance, Special Issue On the Origin of Fictions: Interdisciplinary Perspectives 30 (1/2): 144-59.

Hiebert, T. (2008) 'Nonsense Interference Patterns,' in Cecchetto, D., Cuthbert, N., Lassonde, J. and Robinson, D. (eds.) Collision: Interarts Practice and Research. UK: Cambridge Scholars Publishing.

Johnson, M. (2009) 'Reply to Mark Turner's "The Scope of Human Thought"' in Comstock, G. (ed.) On the Human. UK: National Humanities Center. http://www.onthehuman.org

Latour, B. (1987) Science in Action: How to Follow Scientists and Engineers through Society. Cambridge: Harvard University Press.

Lazzarini, R. (2000) 'skulls.' New York.

Lenoir, T. (2004) '(Foreword) Haptic Vision: Computation, Media, and Embodiment in Mark Hansen's New Phenomenology,' in New Philosophy for New Media. Cambridge, MA: The MIT Press.

Spivak, G. C. (1974) 'Translator's Preface,' in Of Grammatology. Baltimore: Johns Hopkins University Press.

Théberge, P. (1997) Any Sound You Can Imagine: Making Music/Consuming Technology, Music/Culture: Wesleyan University Press.

Turner, M. (2009) 'The Scope of Human Thought' in Comstock, G. (ed) On The Human. UK: National Humanities Center. http://www.onthehuman.org

Varela, F. (1992) 'Autopoiesis and a Biology of Intentionality,' at Autopoiesis and Perception Workshop, Dublin City University. 
(1999) 'The Specious Present: A Neurophenomenology of Time Consciousness,' in Varela, F., Petitot, J., Pachoud, B. and Roy, J.-M. (eds.) Naturalizing Phenomenology: Issues in Contemporary Phenomenology and Cognitive Science. Stanford, CA: Stanford University Press.

Wolfe, C. (2010) What Is Posthumanism? Minneapolis: University of Minnesota Press.

David Cecchetto is Assistant Professor of New Media History and Criticism at OCAD University in Toronto, Canada, where his research critiques constructions of technological posthumanism. Readings of sound-based media art are often featured prominently in David's writing, specifically in service of a general project of reversing the flow of theory to practice. David's publication record includes articles, book chapters, and a co-edited collection. His artistic work - in analogue and digital media - has been presented in Canada, the United States, the United Kingdom, Mexico, and Russia. www.davidcecchetto.net 